\title{
THE SHORTEST PERCEPTIBLE TIME-INTERVAL BETWEEN TWO FLASHES OF LIGHT ${ }^{1}$
}

\section{BY KNIGHT DUNLAP}

The Johns Hopkins University

The determination of the minimal perceptible time-interval: the shortest interval between two stimuli which allows the stimuli to be perceived as successive, and not simultaneous is important for many lines of work, including problems of time-perception and rhythm and also problems of rateperception. Moreover an important theory of psychic synthesis has been supported by interpretations of certain measurements of the time-threshold for disparate stimulations (i.e., stimulations of two modes of sense in succession).

My interest in these several lines of research, and also in certain purely visual phenomena, led me to commence, in the summer of 1912 , an investigation of the time-threshold for visual stimulation, and its relation to the 'critical frequency' of flicker and fusion. The result of that summer's work (done at the Johns Hopkins University, with myself as principal observer), encouraged me to attempt further work on the problem with better apparatus. During the next college year (1913-1914) a graduate student was allowed to take up the problem, and obtained some results which seemed important. ${ }^{2}$ This student, on leaving the University, took his unelaborated results 'with him, and I have not since been able to obtain them. Last summer, having the opportunity to work in Dr. Hyde's laboratory, I took up the problem again with specially constructed apparatus and obtained results which are interesting and important. I shall give in the following paper the results of both of my experiments.

1 From the Nela Research Laboratory, National Lamp Works of the General Electric Company.

2 This work was done with a pendulum apparatus, giving great accuracy, and having other advantages over the rotation apparatus first used; but with some difficulties of manipulation. 
The first work on the visual time-threshold was done by Exner, ${ }^{1}$ who worked with electric sparks, and found thresholds of $44 \sigma$ at $280 \mathrm{~mm}$. distance, and $21 \sigma$ at $640 \mathrm{~mm}$. Weyer, ${ }^{2}$ in Wundt's laboratory, found a much lower threshold, I $2 \sigma$. Weyer also found, using electric sparks, a flicker-threshold from $25 \sigma$ to $87 \sigma$, according to the adaptation and other conditions, and a threshold for separation of a series from $42 \sigma$ to $105 \sigma$.

Shortly before my work was begun Bassler published the results of some of his investigations, in which he found the time-threshold (length of shortest perceptible dark interval) to be about $40 \sigma$ with two visual stimulations, and the flicker point to be about one third as much (for serial stimulation).

None of these results are very significant, the work with electric sparks suffering from lack of control, and Bassler's being affected by serious defects of method.

Bassler used black discs on which were either two white sectors or a regularly spaced series, and rotated the disc close behind a screen in which was a hole a centimeter and a half in diameter. This hole, in which the alternation of black and white occurred, was observed from an unspecified distance. A student in our laboratory reproduced Bassler's apparatus, as nearly as Bassler's description allowed, and we found that eye movement was a very important factor in the observation, the eye movement being induced or increased by the motion of the black and white edges as they traveled across the aperture.

\section{Preliminary Work ${ }^{4}$}

It is obvious that the proper attack on the problem of the visual time-threshold involves control of the intensity and the duration of the flashes of light, and of the adaptation and movement of the eye, as well as of the areas stimulated.

In my first experiment $I$ succeeded in eliminating the most

1 Exner, Pfüger's Archio, XI., S. 407.

2 Weyer, Philos. Studien, XV., S. 67-138.

'Bassler, Pfinger's Archio, 191 I, Bd. 43, 245-25I.

- This work was reported before the Natural Academy of Sciences, November 19, 1913. See abstract in Science, 1913, Vol. 38, p. 699. 
serious important cause of eye movement, namely the traveling of the illumination across the area of stimulation, and kept the illumination constant and the eye dark-adapted. The first factor which I wished to investigate was the effect of the duration of the flashes, and the second was the effect of the intensity.

For simplicity's sake I adopted the method of rotating sectors, measuring the time interval by determining the speed of rotation, and computing from the angular width of the sectors. This method has two serious disadvantages: first, the change in speed, which is necessary to vary the length of the interval between flashes, varies the length of the flashes also, so that the effect of absolute flash length cannot be easily determined, relative length only being controllable. Second, the pair of flashes is necessarily repeated rapidly again and again unless some special device is used to cut off the exposure on all but one round of the disc; and this repetition is a factor which adds greatly to the difficulty of the determination.

My apparatus consisted of a Nernst glower, enclosed in a metal box, with a lens; a disc of white plaster of paris; a motor of controllable rate, driving, by a reducing belt, a spindle on which discs of adjustable sectors could be rotated; and an Ewald chronoscope for counting the rotations of the spindle during a given time.

The lens, $83 \mathrm{~cm}$. from the Nernst glower, focused the light into an image, of approximately the same size as the glower, in the plane of the surface of the rotating sectors on the spindle, with the long axis of the image in a radius of rotation. When not interrupted by the sectors, the light fell on the plaster surface placed $35 \mathrm{~cm}$. beyond the focus, forming a nearly rectangular spot 3.5 by $5 \mathrm{~cm}$. The brightness of this spot was not measured, but was kept constant by maintaining a constant current through the Nernst glower, and by frequently inserting a Lümmer-Brodhun photometer in the position of the disc, comparing the illumination of the Nernst with that of a standardized 8 c.p. carbon lamp. The two brightnesses used were equal to those produced on the same 
surface by the $8 \mathrm{c.p}$. lamp at $36.5 \mathrm{~cm}$. and $67.5 \mathrm{~cm} .^{1}$ respectively. Since the rotating sectors moved across the beam of light at the focus, 'traveling' of the illuminated areas was nearly eliminated; since the focused image was narrow, the time between the beginning of the illumination (or the dark period) and the full illumination (or complete cut-off) was so small as to be negligible.

The observer (myself in most cases) sat between 75 and $80 \mathrm{~cm}$. from the plaster surface, the angle between his line of sight and the axis of the Nernst beam being 45 degrees. The plane of the plaster surface was so placed that it made equal angles with the axis of the beam and the line of sight.

With this apparatus I made determinations both of the time-threshold for two flashes, and of the critical frequency for a series of interruptions. In the flicker work, a different disc, with the appropriate sectors cut out, was used for each of the different ratios of light to dark interval. In the work on time-threshold, a combination of sectors was used, giving two openings, from $0^{\circ}$ to $90^{\circ}$ in width, separated by a $5^{\circ}$ sector or by a $10^{\circ}$ sector. The lengths of flash used with the $5^{\circ}$ interval were $5^{\circ}, 10^{\circ}$, and by $10^{\circ}$ steps to $90^{\circ}$ : with the $10^{\circ}$ interval, flashes of $2.5^{\circ}, 5^{\circ}$ and $10^{\circ}$ were used, also several greater lengths, up to $180^{\circ}$ for one flash, the other being shorter. The flicker discs (fifteen in number) had each two apertures, with ratios of open to closed ranging between $\mathrm{I} / 35$ to $35 / \mathbf{r}$.

In working on myself the method was as follows: starting with a speed of rotation such that distinct doubleness (or flicker) was observable, the speed was increased by small steps until a single flash (or fusion) was obtained. Then, by depressing a key a circuit was completed through the Ewald, and a circuit-breaker on the spindle, and was allowed to continue for ten seconds: thus the number of rotations in ten seconds was registered. After recording the speed, it was increased somewhat (the amount of increase at this point being purposely irregular), and then decreased by small steps

1 That is, in the first case, the lamp at $36 \mathrm{~cm}$. gave a brightness clearly brighter than that of the Nernst beam, and at $37 \mathrm{~cm}$. a brightness clearly less. 
until the point of doubleness (or flicker) was reached, when the speed was again measured. Three determinations were usually made on each setting of the sectors (or each flickerdisc), before proceeding to the next. The longer series of settings, or series of discs, was gone through with in this way from one to two hours, and as one such series a day was all an observer could endure, the progress of the experiment was necessarily slow.

The observer was instructed to make his judgment each time rather quickly, and then look away until the speed was changed. Continued gazing at the lighted area was found to cause even a pronounced doubleness or flicker to disappear. ${ }^{1}$

The observations were made with darkness adaptation. In working on myself, I took the speed readings, and made the record, by a very dim light, and then waited for a minute or so for readaptation. This procedure undoubtedly had some effect on the determinations, but this effect was probably not large.

The series of settings in the groups were taken in different orders on different days, the several orders being carefully

TABLE I

Flicker and Fusion

Observer Dunlap

\begin{tabular}{|c|c|c|c|c|c|c|c|c|c|}
\hline \multicolumn{2}{|c|}{ Secton in Degrees } & \multicolumn{4}{|c|}{ Cycles per Second } & \multicolumn{4}{|c|}{ Durations in Sigmas } \\
\hline \multirow{2}{*}{ Closed } & \multirow{2}{*}{ Open } & \multirow{2}{*}{ Flicker } & \multirow{2}{*}{ M.V. 4} & \multirow{2}{*}{ Fusion } & \multirow{2}{*}{ M.V.\$ } & \multicolumn{2}{|c|}{ Flucker } & \multicolumn{2}{|c|}{ Fusion } \\
\hline & & & & & & Closed & Open & Closed & Open \\
\hline 5 & 175 & 24.12 & 5.86 & 28.17 & 5.93 & 1.15 & 40.29 & 0.98 & $34.4^{8}$ \\
\hline 10 & 170 & 28.11 & 4.20 & 31.9 & 4.48 & 1.97 & 33.59 & 1.73 & 29.53 \\
\hline 15 & 165 & 31.08 & $5.5 \mathrm{I}$ & 36.00 & 5.25 & 2.68 & 29.49 & $2.3 \mathrm{I}$ & 25.45 \\
\hline 30 & 150 & 38.56 & 5.16 & 42.59 & 5.62 & 4.32 & 21.60 & 3.91 & 19.56 \\
\hline 45 & 135 & 42.59 & $3.5 \mathrm{I}$ & 46.25 & 4.15 & 5.86 & 17.60 & 5.40 & $16.2 \mathrm{I}$ \\
\hline 60 & 120 & 43.84 & 3.55 & 47.94 & 4.69 & 7.60 & 15.20 & 6.95 & 13.90 \\
\hline 75 & 105 & 44.68 & 4.00 & 49.46 & 4.38 & 9.32 & 13.05 & 8.42 & II. 79 \\
\hline 90 & 90 & 45.32 & 3.07 & 49.47 & $4 \cdot 34$ & II.03 & 11.03 & 10.10 & 10.10 \\
\hline 105 & 75 & 45.64 & 4.07 & 50.22 & 4.60 & 12.00 & 9.12 & II.6I & 8.29 \\
\hline 120 & 60 & 44.81 & 3.70 & 49.75 & 4.94 & 14.87 & 7.43 & 13.39 & 6.69 \\
\hline 135 & 45 & $44.5^{8}$ & 4.23 & 49.00 & 4.13 & 16.82 & 5.60 & 15.30 & 5.10 \\
\hline 150 & 30 & 41.58 & 4.72 & 46.73 & 3.38 & 20.03 & 4.00 & 17.83 & 3.56 \\
\hline 165 & 15 & 38.72 & 4.57 & 42.92 & 5.65 & 23.66 & 2.15 & 21.35 & 1.94 \\
\hline 170 & 10 & 35.66 & 5.39 & 39.80 & 4.98 & 25.48 & 1.55 & 23.72 & 1.39 \\
\hline$\times 75$ & 5 & $29.6 I$ & 6.42 & 34.04 & 6.06 & 32.82 & 0.93 & 28.55 & $0.8 \mathrm{I}$ \\
\hline
\end{tabular}

1 'This 'flicker adaptation' is not due to brightness adaptation, as later work shows. 
TABLE II

Time Threshold. Standard Brugrtwess

Observer Dunlap

1. $A=C, B=5$.

\begin{tabular}{c|r|r|r|r|r|r}
\hline & \multicolumn{3}{|c|}{ Double } & \multicolumn{3}{|c|}{ Single } \\
\cline { 2 - 7 }$A^{\circ}=C^{\circ}$ & $B_{\sigma}$ & M.V. & $A=C_{\sigma}$ & $B_{\sigma}$ & M.V. & $A=C_{\sigma}$ \\
\hline 5 & 19.8 & 8.0 & 19.8 & 13.8 & 12.3 & 13.8 \\
10 & 14.9 & 10.7 & 29.8 & 11.1 & 9.9 & 22.2 \\
20 & 10.5 & 7.9 & 42.3 & 8.2 & 7.9 & 32.8 \\
30 & 7.3 & 14.7 & 43.8 & 6.2 & 9.1 & 37.3 \\
40 & 6.3 & 13.5 & 50.9 & 5.2 & 10.7 & 41.7 \\
50 & 5.4 & 11.8 & 54.6 & 4.5 & 13.3 & 4.59 \\
60 & 4.8 & 10.1 & 58.5 & 4.1 & 11.2 & 50.0 \\
70 & 4.4 & 10.7 & 62.3 & 3.7 & 6.3 & 52.9 \\
80 & 4.3 & 9.4 & 69.6 & 3.7 & 7.4 & 60.4 \\
90 & 4.0 & 8.4 & 72.9 & 3.5 & 9.9 & 63.5 \\
\hline
\end{tabular}

2. $A=C, B=$ Io.

\begin{tabular}{c|c|c|c|c|c|c}
\hline$A^{\circ}=C^{\circ}$ & $B_{\sigma}$ & M.V. & $A \sigma$ & $B \sigma$ & M.V. & $A_{\sigma}$ \\
\hline 2.5 & 28.1 & 17.8 & 7.0 & 20.9 & 16.5 & 5.2 \\
5 & 27.0 & 11.6 & 13.5 & 19.2 & 13.8 & 9.6 \\
10 & 20.6 & 8.7 & 20.6 & 15.9 & 11.7 & 15.9 \\
\hline
\end{tabular}

3. $B=5, C=5$.

\begin{tabular}{c|c|c|c|c|c|c}
\hline$A^{\circ}$ & $B_{\sigma}$ & M.V.\$ & $A \sigma$ & $B \sigma$ & M.V.\$ & $A \sigma$ \\
\hline 10 & 16.0 & 11.5 & 33.1 & 11.9 & 6.2 & 23.8 \\
30 & 11.8 & 5.7 & 71.1 & 9.4 & 9.1 & 56.7 \\
50 & 8.8 & 8.1 & 88.3 & 7.0 & 4.6 & 70.8 \\
70 & 6.6 & 7.2 & 92.5 & 5.6 & 8.6 & 78.9 \\
90 & 5.3 & 7.8 & 96.1 & 4.6 & 8.1 & 84.4 \\
\hline
\end{tabular}

4. $A=10, B=10$.

\begin{tabular}{r|c|c|c|c|c|c}
\hline$C^{0}$ & $B_{\sigma}$ & M.V. & $C_{\sigma}$ & $B_{\sigma}$ & M.V.4 & $C_{\sigma}$ \\
\hline 20 & 20.8 & 10.6 & 41.7 & 16.3 & 7.8 & 32.6 \\
60 & 22.2 & 18.4 & 133.5 & 16.8 & 9.2 & I17.7 \\
100 & 24.3 & 8.9 & 243.6 & 18.1 & 7.5 & 181.3 \\
140 & 23.9 & 11.3 & 335.2 & 18.0 & 8.9 & 252.5 \\
180 & 21.9 & 7.5 & 393.3 & 15.6 & 13.9 & 280.8 \\
\hline
\end{tabular}

planned to distribute the effects of practice over the whole series.

The results of my observations are presented in Tables I., II. and III. In Table I. the average flicker-points and fusion-points for the several ratios of open to closed sectors are given both in cycles per second (i.e., the number of complete changes from dark to light and back to light again in a second); and also in the duration in thousandths of a second, of the individual light and dark periods. 
In Tables II. and III. the average durations are given for ' $A$ ' (the first flash), ' $B$ ' (the dark intermediate interval) and ' $C$ ' (the second flash) when the flashes appeared discontinuous ('double'), and when they appeared as one uniform flash ('single'). Table II. gives results of work with the higher brightness described above; Table III., with the lower brightness.

TABLE III

Time Thresholds, Low Brightwess

Observer Duniap

$A=C, B=5$.

\begin{tabular}{c|c|c|c|c|c|c}
\hline$A^{\circ}=C^{\circ}$ & $B_{\sigma}$ & M.V. & $A=C_{\sigma}$ & $B_{\sigma}$ & M.V.X & $A=C_{\sigma}$ \\
\cline { 2 - 6 } & 20.5 & 10.7 & 20.5 & 12.4 & 9.42 & 12.4 \\
55 & 8.9 & 7.6 & 53.9 & 7.2 & 5.6 & 43.3 \\
70 & 4.5 & 7.8 & 63.1 & 4.0 & 4.8 & 56.8 \\
\hline
\end{tabular}

TABLE IV

True Thresholds: Low Brightness

Observer G. $R$. Wells

r. $A=C, B=5$

\begin{tabular}{|c|c|c|c|c|c|c|}
\hline \multirow{2}{*}{$A^{\circ}=C^{\circ}$} & \multicolumn{3}{|c|}{ Double } & \multicolumn{3}{|c|}{ Single } \\
\hline & $B \sigma$ & M. V., & $A=C_{\sigma}$ & Bo & M. V. .6 & $A=C_{0}$ \\
\hline $\begin{array}{l}10 \\
30 \\
50 \\
\end{array}$ & $\begin{array}{r}19.9 \\
10.5 \\
7.1 \\
\end{array}$ & $\begin{array}{r}11.0 \\
9.3 \\
10.0 \\
\end{array}$ & $\begin{array}{l}39.9 \\
63.1 \\
71.7 \\
\end{array}$ & $\begin{array}{r}13.9 \\
8.1 \\
5.5 \\
\end{array}$ & $\begin{array}{r}5.7 \\
10.3 \\
10.7 \\
\end{array}$ & $\begin{array}{l}27.9 \\
49.1 \\
55.6 \\
\end{array}$ \\
\hline \multicolumn{7}{|c|}{ 2. $C=10, B=5$} \\
\hline$A^{\mathcal{O}}$ & Bo & M. V. 4 & Ao & $B_{\sigma}$ & M. V.6 & $A \sigma$ \\
\hline $\begin{array}{l}30 \\
50\end{array}$ & $\begin{array}{l}13.1 \\
11.2 \\
\end{array}$ & $\begin{array}{r}11.8 \\
9.0 \\
\end{array}$ & $\begin{array}{r}78.9 \\
112.4 \\
\end{array}$ & $\begin{array}{r}9.9 \\
8.0 \\
\end{array}$ & $\begin{array}{l}9.2 \\
8.6 \\
\end{array}$ & $\begin{array}{r}59.5 \\
80.7 \\
\end{array}$ \\
\hline \multicolumn{7}{|c|}{ 3. $A=\mathrm{10}, B=5$} \\
\hline $\begin{array}{l}30 \\
50 \\
\end{array}$ & $\begin{array}{l}18.8 \\
19.5 \\
\end{array}$ & $\begin{array}{r}10.7 \\
6.3 \\
\end{array}$ & $\begin{array}{l}113.3 \\
195.6 \\
\end{array}$ & $\begin{array}{r}14.9 \\
15.0 \\
\end{array}$ & $\begin{array}{r}8.6 \\
9.7 \\
\end{array}$ & $\begin{array}{r}89.6 \\
150.1 \\
\end{array}$ \\
\hline
\end{tabular}

In Tables IV. and V. the results of observations of two other persons are given. These observations were made after I had finished mine, and it was not deemed necessary to use all the flash-lengths which I had observed. In these cases I manipulated the apparatus and recorded the measurements, so that the observers worked under better conditions 
TABLE V

The Tyresfolos

Obseroer H. M. Johnson.

1. Standard Brightness

\begin{tabular}{|c|c|c|c|c|c|c|}
\hline \multirow{2}{*}{$A^{\circ}=C^{\circ}$} & \multicolumn{3}{|c|}{ Double } & \multicolumn{3}{|c|}{ Single } \\
\hline & Bo & M. V. $\%$ & $A=C_{\sigma}$ & $B_{\sigma}$ & M. v. & $A=C_{0}$ \\
\hline $\begin{array}{r}5 \\
10 \\
30 \\
50 \\
70 \\
\end{array}$ & $\begin{array}{r}16.6 \\
9.4 \\
7.0 \\
5.2 \\
45 \\
\end{array}$ & $\begin{array}{r}\text { I4.2 } \\
\text { I2.1 } \\
\text { I0.0 } \\
8.0 \\
8.6 \\
\end{array}$ & $\begin{array}{l}16.6 \\
18.8 \\
42.2 \\
52.4 \\
63.1 \\
\end{array}$ & $\begin{array}{r}32.1 \\
7.8 \\
5.8 \\
4.3 \\
3.8 \\
\end{array}$ & $\begin{array}{r}9.3 \\
r 2.2 \\
8.9 \\
4.8 \\
9.1 \\
\end{array}$ & $\begin{array}{l}12.1 \\
15.6 \\
34.8 \\
43.4 \\
54.5\end{array}$ \\
\hline \multicolumn{7}{|c|}{ 2. Lower Brightness } \\
\hline $\begin{array}{r}5 \\
30\end{array}$ & $\begin{array}{r}13.2 \\
7.0\end{array}$ & $\begin{array}{r}7.1 \\
13.1\end{array}$ & $\begin{array}{l}13.2 \\
42.0\end{array}$ & $\begin{array}{r}20.3 \\
5.8\end{array}$ & $\begin{array}{l}5.7 \\
9.2\end{array}$ & $\begin{array}{l}10.3 \\
35.2\end{array}$ \\
\hline
\end{tabular}

than those under which I observed, specifically as regards adaptation.

Each of the values given in Tables I., II., III. and V. are averages of twenty-five thresholds. The values in Table IV. are averages of twenty thresholds.

There are two points of importance which stand out in these data. First, the rise in rate of the 'critical frequency' (flicker and fusion points) from the extreme inequality to equality of open and closed sectors, in both directions (Table II.). Second, the decrease of the time threshold with increase in the length of the first flash (Tables II., IV. and V.). This decrease seems to be altogether a function of the first flash; increasing the length of the first flash with the second flash constant (II., 3; IV., 2) has almost the effect of increasing both flashes; while increasing the length of the second flash (II., 4; IV., 3) alone has practically no effect. The slight increase in the threshold in both these cases is due to the increased difficulty of observation with the unequal length and hence unequal appearing brightness of the flashes.

In addition to these points, it is to be noted that the time thresholds are low, ranging (with equal flashes) from 4 to 20 sigmas. The comparison of these figures with those obtained in other experiments is, however, not now significant, since we have not as yet analyzed the various factors entering into 
determinations of this sort. In addition to the brightness, in regard to which the above data are not significant, the factor of adaptation is probably extremely potent. These results were obtained with fairly good darkness adaptation; they cannot be compared with results obtained with daylight adaptation.

Among the factors affecting the formation of judgments, the rapid repetition of the pair of flashes was conspicuously disturbing. The simple rotation apparatus is not suited to determinations of this kind.

\section{Work on Brightness and Adaptation}

The second set of experiments I varried on, at Dr. Hyde's invitation, in the Nela Research Laboratory during the summer months of 1914. In carrying out these experiments I received much help from the staff of the laboratory, and I am especially indebted to Dr. Hyde, the director of the laboratory; to Mr. Cady, assistant director; to Dr. Lorenz; to Dr. Cobb; and to Dr. Johnson. The readiness of the members of the staff to give their time to my problems, and to release to me apparatus from their own experiments, made possible such work as I was able to accomplish in the short time I was there. The greatest burden of the observations fell on Mr. Eric Martienssen, to whom I am indebted for his careful and willing work, under conditions which were sometimes trying.

My apparatus, which need not be described in detail, consisted of the following units.

(a) A double rotator, ${ }^{1}$ carrying on one axis of rotation two arbors; one on the main shaft and the other on a sleeve on that shaft, the sleeve being geared to an auxiliary shaft and that back to the main shaft, so that the sleeve made one rotation for nine of the shaft. The arbor on the sleeve carried a large metal disc with a 40-degree aperture. Variable cardboard sectors were carried by the faster moving arbor. When the axis of light is parallel to the shaft of this apparatus,

2 This piece of apparatus was made under my direction in the Physics workshop of The Johns Hopkins University. 
whatever exposures are arranged through sectors on the faster arbor are repeated every ninth revolution of the shaft, being cut out the remainder of the time by the slow moving disc.

The main shaft carried also a loose gear, in mesh with a gear on the driving motor; with an electro-magnetic clutch of my devising, so that the disc and sectors could be stopped for adjustment without stopping the driving motor; and could be started again without jerk by turning the current gradually on the clutch magnet. The same shaft also carried a cylinder of brass and hard rubber, on which rested two brass brushes, so that the rotations could be counted by a step-up mechanism operated by the make-and-break of the circuit.

(b) A nitrogen-filled lamp, with the wire in a straight compact coil; operated in these experiments at $85,120,200$ 289 and 400 watts. The image of the coiled wire was focused, by suitable lenses, on a slit, to cut off light reflected from the surface of the lamp bulb; and by other lenses refocused in the plane of the sectors carried on the faster moving arbor of the rotation apparatus described above. The axis of the beam of light was parallel to the shaft of the rotation apparatus, and the long axis of the image was radial to the shaft.

The lamp, the slit and the lenses were enclosed in a large hood of black felt drawn over a wooden framework, with an aperture just large enough for the convergent beam to emerge.

(c) A movable screen located just beyond the slow-moving disc of the rotator and operated by a hand lever. By raising this screen shortly before the disc made an exposure, and lowering it shortly afterwards, a single exposure of the interval arranged through the sectors was allowed. The manipulation of this screen required no accurate timing, since the slow disc allowed exposure every ninth rotation of the sectors only.

(d) A lens, just beyond the hand screen, decreased the divergence of the cone of light, increasing the brightness of the surface illuminated.

(e) A plaster disc, surfaced with magnesia, illuminated by the cone of light. This disc was $12.5 \mathrm{~cm}$. in diameter, and 
about half the diameter of the light cone at the point of insertion of the disc and had a background of black velvet upon which the light around the disc was negligible. The plane of the disc was vertical, but was at an angle of $30^{\circ}$ from the plane perpendicular to the axis of the cone of light.

The observer sat so that his binocular line of sight was perpendicular to the disc, which was about $165 \mathrm{~cm}$. from his eyes.

(f) A miniature projection lamp, with a small incandescent bulb entirely enclosed, established out of the range of the observer's vision, cast on the object disc a group of four small dots, which served excellently as a fixation mark.

(g) Eight mazda lamps, totalling 600 watts, so disposed in the room that the walls were illuminated, especially the wall in front of the observer-the wall behind the plaster disc-but the lamps were screened from the observer's eyes. These lamps were controlled by a single switch.

(h) A single mazda lamp in a long black cardboard tunnel, arranged to throw continuous illumination, when desired, on the disc.

(i) An Ewald chronoscope, for counting the rotations of the sectors, as a control of the accuracy.

(j) A synchronous motor ${ }^{1}$ for driving the rotator. This had eight poles, and working on 60 cycle A.C. current gave 15 rotations per second. This motor was geared to the main shaft of the rotator $(a)$, the ratio to the gear on the motor shaft being $I$ to 3 . The main shaft therefore made five rotations per second, so that for the sectors carried by the arbor on the main shaft $9^{\circ}$ equalled $5 \sigma$. The variations in speed, due to variations in current frequency, were negligible during the periods of work.

(k) A small D.C. motor for starting the synchronous motor. This starting motor was belted to a one-flanged pulley on the shaft of the synchronous motor so that the belt could be thrown off when the synchronous motor was working properly. A stroboscope disc mounted on the same shaft, and illuminated by a I5-watt lamp on the A.C. current,

1 This motor was one which Dr. Lorenz had constructed for his use. The stroboscopic method of starting the motor was also suggested by him. 
indicates the proper moment for turning on the synchronous motor.

The five wattages used on the lamp gave brightnesses on the object disc of $3,10,36,82$ and 168 candles per square meter. This range of illuminations seemed adequate for the investigation of the effects of brightness, which was the first point I had planned to attack.

The results of the preliminary experiment, reported above, had shown clearly that the threshold for doubleness (measured in terms of the dark interval) depends on the length of the flashes, especially of the first flash, although the absolute magnitudes of the thresholds as determined in those experiments could not be supposed to be very significant. It would therefore be possible, theoretically, to determine thresholds in either of two ways: first, by keeping the dark interval constant and varying the flashes; and second, by keeping the flashes constant and varying the dark interval. It would seem equally useful to work out the thresholds in fiash length for several fixed dark-interval lengths, and to work out the thresholds in dark-interval length for several fixed flash-lengths. In either case the effect of the brightness, and of adaptation could (it would seem) be worked out in an adequate way.

In the manipulation of apparatus, the first procedure is far the simpler. The sector adjustments are not so complicated, and hence the progress of the experiment should be more rapid. Realizing that the work would at best be slow, I chose the plan which offered this important advantage.

Observations were made at first with dark adaptation exclusively. The subject was kept in the room from ten to twenty minutes before commencing work, according as he had come in from outdoors, or from more or less dimly lighted work rooms. No warning signal other than the normal sound of the electro-magnetic clutch in taking hold, was needed by the observer. The motor ran continuously, and the clutch was thrown in when an observation was desired. The rotator 'picked up' full speed in less than a second; the hand screen was lifted about two seconds after 
the clutch was thrown in. The four dots of light in the center of the disc fixed the line of sight before the flashes occurred. Four repetitions of the exposure were given in succession, but the observer usually gave his judgment after the second or third.

Observations were carried on for some time by Martienssen and myself by this method, using the procedure of 'serial groups,' but the results, although interesting, were of little value for the purposes of the experiment. Variations in the durations of the flashes produced variations in the apparent brightness and apparent color of the disc, which were at first extremely confusing, and on which finally the judgments came to depend, rather than on any real appearance of 'doubleness' or 'singleness.' One set of five hundred judgments by Martienssen, which are typical, are given in Table VI.

\section{TABLE VI}

\section{Martienssen}

Dark interval 25\%. Brightness 82 c. per sq. m.

\begin{tabular}{c|c|c|c|c|c}
\hline Two Flarthes & Double & Single & One Flasb & Double & Single \\
\hline 700 & 48 & 2 & 1400 & 0 & 50 \\
60 & 36 & 14 & 120 & 0 & 50 \\
60 & 38 & 12 & 100 & 3 & 47 \\
40 & 32 & 18 & 80 & 11 & 39 \\
30 & 41 & 9 & 60 & 12 & 38 \\
\hline
\end{tabular}

In this table the first column gives the length of flash where two were used, the second and third columns giving the number of judgments of double and single for each flashduration. The fourth column gives the durations of the single flashes, each equal to the sums of the two in the corresponding pair; the fifth and sixth columns giving the number of judgments of single and double respectively for each of these single flash durations.

The increasing difficulty of discrimination is here shown, not so much by the increased tendency to call the double flashes single, as by the tendency to call the single flashes double. Obviously, no definite threshold can be determined 
when this tendency is present. ${ }^{1}$ This tendency, it must be noted, is not due to mere confusion; as we shall see later, a single flash often appears distinctly double, and with the same sort of doubleness as is noticed in a really double flash. In this particular set of observations, however, the judgments, according to the observer's report, were based largely on differences in apparent brightness and color; at least this seemed to him to be the case in the latter part of the set.

TABle VII

\section{Martienssen}

Dark interval 25\%. Brightness, 3 c. per sq. $\mathrm{m}$.

\begin{tabular}{c|c|c|c|c|c}
\hline Two Fleshe & Double & Single & One Finsh & Double & Single \\
\hline 500 & 26 & 4 & 1060 & 3 & 23 \\
50 & 16 & 4 & 80 & 4 & 16 \\
30 & 18 & 2 & 60 & 2 & 18 \\
20 & 15 & 5 & 40 & 4 & 16 \\
10 & 15 & 5 & 20 & 11 & 9 \\
\hline
\end{tabular}

The results of a set of observations by Martienssen with lower brightness are given in Table VII. Results of a set of observations by Dr. Johnson on the moderate brightness are given in Table VIII. Other sets with different brightnesss gave results of the same order.

\section{TABLE VIII}

\section{Johnson}

Dark interval 25\%. Brightness, 82 c. per 8q. m.

\begin{tabular}{c|c|c|c|c|c}
\hline Two Flashes & Double & Single & One Flash & Double & Single \\
\hline $50 \sigma$ & 20 & 0 & $100 \sigma$ & 1 & 19 \\
40 & 17 & 3 & 80 & 7 & 13 \\
30 & 23 & 7 & 60 & 4 & 26 \\
20 & 10 & 10 & 40 & 5 & 15 \\
\hline
\end{tabular}

In this set of observations, the observer's judgment was influenced very largely by the apparent duration of the total

1 This condition is similar to that found in attempting to determine the "two point' threshold by simultaneous stimulation of the skin. No threshold can be determined, since one stimulation frequently is perceived as two, and hence the least separation of two points giving a certain percentage of perception of two has no definite significance. 
exposure; the greater duration of the two flashes was noticed, especially with the shorter flash-lengths, and this tended more and more to become the criterion of doubleness.

The procedure by groups ('method of serial groups'), it was clear, could not be used in this experiment. The secondary criteria-in this case the differences in brightness, color, and duration-are made maximally conspicuous by this method, and judgments strictly on the points under examination are made practically impossible. I therefore attempted to use the shuffled series procedure, still clinging to the method of constant dark interval. A few series, however, showed that this method was not practicable, even when the better procedure was employed, since the differences in brightnesses and color still were very conspicuous. The regular progression procedure ('method of minimal change') accentuated these secondary criteria still more.

The effects of the total duration had been foreseen, and I had expected to introduce variations in which the single flash should be equal in length to the two flashes plus the dark interval. This variation was found to be inapplicable because it would have accentuated the brightness differences. For example; the greater brightness of the $100 \sigma$ flash as compared with the two successive flashes of $50 \sigma$ with $25 \sigma$ dark interval, would be still greater if the lengths of the two flashes were reduced to $37.5 \sigma$ each.

The next attempts were made by the method of constant flash-length, using the 'shuffled series' procedure. With this method the differences in apparent brightness are not so marked as with the constant dark-interval method, and by this procedure these differences and the differences in duration are not so disturbing as they are in the serial group procedure. It is possible, in other words, to form judgments on the apparent doubleness or singleness alone of the flashes, although it required a high degree of training in order to eliminate absolutely other criteria.

The results of these next observations by the shuffled series procedure are given in Tables IX., X., XI. and XII. In these tables the first column gives the separation of the 
two flashes, and the other columns give the number of judgments of 'single' and 'double' for each of the five brightnesses. The observations with all of the brightnesses were obtained on the same days, a series being taken with each brightness during each experimental period, the order of brightness being altered from day to day in a regular way.

Tabie IX

Martienssen

Flash $=500$

\begin{tabular}{|c|c|c|c|c|c|c|c|c|c|c|}
\hline \multirow{3}{*}{ Intervals, o } & \multicolumn{10}{|c|}{ Brigbenesses, Candles per Sq. Meter } \\
\hline & \multicolumn{2}{|c|}{3} & \multicolumn{2}{|c|}{ yo } & \multicolumn{2}{|c|}{36} & \multicolumn{2}{|c|}{82} & \multicolumn{2}{|c|}{268} \\
\hline & d. & .. & d. & s. & d. & s. & d. & *. & d. & .. \\
\hline $\begin{array}{r}0 \\
5 \\
10 \\
15 \\
20 \\
25\end{array}$ & $\begin{array}{r}\text { II } \\
8 \\
6 \\
9 \\
\text { 10 } \\
\text { II }\end{array}$ & $\begin{array}{r}13 \\
4 \\
6 \\
3 \\
2 \\
1\end{array}$ & $\begin{array}{l}5 \\
5 \\
7 \\
5 \\
4 \\
8\end{array}$ & $\begin{array}{r}15 \\
5 \\
3 \\
5 \\
6 \\
2\end{array}$ & $\begin{array}{r}9 \\
9 \\
5 \\
9 \\
11 \\
10\end{array}$ & $\begin{array}{r}15 \\
3 \\
7 \\
3 \\
1 \\
2\end{array}$ & $\begin{array}{r}11 \\
5 \\
7 \\
6 \\
8 \\
10\end{array}$ & $\begin{array}{l}9 \\
5 \\
3 \\
4 \\
2 \\
0\end{array}$ & $\begin{array}{l}5 \\
7 \\
8 \\
9 \\
6 \\
8\end{array}$ & $\begin{array}{r}19 \\
5 \\
4 \\
3 \\
6 \\
4\end{array}$ \\
\hline
\end{tabular}

TABLE $X$

Johnson

Flash $=500$

\begin{tabular}{|c|c|c|c|c|c|c|}
\hline \multirow{3}{*}{ Intervals, $\sigma$} & \multicolumn{6}{|c|}{ Brightnesses, Candles per Sq. Meter } \\
\hline & \multicolumn{2}{|c|}{3} & \multicolumn{2}{|c|}{ Io } & \multicolumn{2}{|c|}{168} \\
\hline & d. & s. & d. & s. & d. & 8. \\
\hline $\begin{array}{r}0 \\
5 \\
10 \\
15 \\
20 \\
25\end{array}$ & $\begin{array}{r}4 \\
5 \\
7 \\
8 \\
10 \\
10\end{array}$ & $\begin{array}{r}16 \\
5 \\
3 \\
2 \\
0 \\
0\end{array}$ & $\begin{array}{l}0 \\
0 \\
2 \\
4 \\
9 \\
8\end{array}$ & $\begin{array}{c}20 \\
10 \\
8 \\
6 \\
1 \\
2\end{array}$ & $\begin{array}{r}0 \\
2 \\
3 \\
8 \\
9 \\
10\end{array}$ & $\begin{array}{r}20 \\
8 \\
7 \\
2 \\
1 \\
0\end{array}$ \\
\hline
\end{tabular}

Other series were taken with light adaptation. In this work the room was lighted by the mazda lamps referred to under $(g)$, and the observer was adapted to the brightness of the plastered wall due to this illumination. When ready to make the observation, the lights were switched off, approximately 1.5 seconds before the exposure of the flashes (or flash). This interval was timed by watching the exposure on the hand-screen; and turning off the lights immediately 
after such exposure. Then the hand-screen was lifted, and since the exposure occurred every 1.8 seconds (the rotationperiod of the slow moving disc) the interval between the turning off of the mazda lamps and the exposure on the object disc was timed sufficiently well.

\section{TABLE XI}

Martienssen

Light Adaptation. Flash $=500$

\begin{tabular}{|c|c|c|c|c|c|c|}
\hline \multirow{3}{*}{ Intervals, . } & \multicolumn{6}{|c|}{ Brightnesses, Candles per Sq. Meter } \\
\hline & \multicolumn{2}{|c|}{3} & \multicolumn{2}{|c|}{$3^{6}$} & \multicolumn{2}{|c|}{268} \\
\hline & d. & s. & d. & s. & d. & s. \\
\hline $\begin{array}{c}0 \\
5 \\
10 . \\
15\end{array}$ & $\begin{array}{r}5 \\
2 \\
15 \\
17\end{array}$ & $\begin{array}{r}25 \\
17 \\
6 \\
2\end{array}$ & $\begin{array}{r}6 \\
12 \\
15 \\
18\end{array}$ & $\begin{array}{r}24 \\
13 \\
5 \\
2\end{array}$ & $\begin{array}{r}3 \\
6 \\
14 \\
19\end{array}$ & $\begin{array}{r}27 \\
14 \\
16 \\
1\end{array}$ \\
\hline
\end{tabular}

TABLE XII

Johnson

Light Adaptation. Flash $=50 \sigma$

\begin{tabular}{|c|c|c|c|c|c|c|}
\hline \multirow{3}{*}{ Intervals, $\sigma$} & \multicolumn{6}{|c|}{ Brightnesses, Candles per Sq. Meter } \\
\hline & \multicolumn{2}{|c|}{3} & \multicolumn{2}{|c|}{36} & \multicolumn{2}{|c|}{168} \\
\hline & d. & s. & d. & s. & d. & s. \\
\hline $\begin{array}{r}0 \\
5 \\
10 \\
15\end{array}$ & $\begin{array}{r}0 \\
5 \\
13 \\
24\end{array}$ & $\begin{array}{r}25 \\
15 \\
6 \\
1\end{array}$ & $\begin{array}{r}2 \\
12 \\
10 \\
16\end{array}$ & $\begin{array}{r}23 \\
13 \\
10 \\
3\end{array}$ & $\begin{array}{r}5 \\
9 \\
18 \\
19\end{array}$ & $\begin{array}{r}20 \\
I I \\
2 \\
I\end{array}$ \\
\hline
\end{tabular}

This method of working with light adaptation seems quite satisfactory. An interval must be allowed between the turning off of the adaptation light and the beginning of the stimulus light, to allow muscular recovery. The one-and-ahalf second period seemed to be about the shortest which could be used. Of course a slight amount of adaptation occurs within this period, but this is kept constant throughout.

Series with darkness adaptation followed the work with light adaptation. Results of one group of series on Martienssen are given in Table XIII. The remainder of the 
work on this observer and on Dr. Johnson was directed to 'feeling out' methods, and does not lend itself to tabulation.

\section{TABLE XIII}

Martienssen

Dark Adaptation. Flash $=250$

\begin{tabular}{|c|c|c|c|c|c|c|}
\hline \multirow{3}{*}{ Intervals, $\sigma$} & \multicolumn{6}{|c|}{ Brigbeness, Cundles per Sq. Meter } \\
\hline & \multicolumn{2}{|c|}{3} & \multicolumn{2}{|c|}{$3^{6}$} & \multicolumn{2}{|c|}{ r68 } \\
\hline & d. & s. & d. & s. & d. & s. \\
\hline $\begin{array}{r}0 \\
15 \\
20 \\
25\end{array}$ & $\begin{array}{r}7 \\
9 \\
13 \\
14\end{array}$ & $\begin{array}{l}7 \\
5 \\
1 \\
0\end{array}$ & $\begin{array}{r}3 \\
9 \\
13 \\
14\end{array}$ & $\begin{array}{r}\text { II } \\
5 \\
1 \\
0\end{array}$ & $\begin{array}{r}\mathbf{I} \\
9 \\
8 \\
\mathbf{1} \mathbf{I}\end{array}$ & $\begin{array}{r}13 \\
5 \\
6 \\
3\end{array}$ \\
\hline
\end{tabular}

From the results, as tabulated, little can be inferred as to the effect of brightness. It is evident that adaptation is an important factor. The factor of greatest consequence, however, is the tendency to see the single flash as double. The effects of this tendency are found in the tabulated results, especially with the lowest brightness, and were still more evident in the work not tabulated. ${ }^{1}$ Attempts to use flashes longer than $50 \sigma$ proved fruitless on account of this tendency. At $75 \sigma$, for example, there was a large increase in the number of 'double' judgments on single stimuli. There is a limit, however, beyond which the double appearance is not found. It may be useful, later, to determine both the upper limit and the lower limit for the fallacious doubling, bet this is a determination of the most difficult sort.

The double appearance of the single flash may, with practice, be distinguished from the true 'doubleness.' That is, there are times when the 'doubleness' of a single flash is clearly different from the 'doubleness' of two successive flashes, if the one and the two are shown with but little pause between. This discrimination is apt to be lost at any time, however, and the pseudo-'doubleness' taken for real 'doubleness.'

As an illustration of the discrimination, the following observation of Dr. Johnson will serve.

1 In many cases, both with one flash and with two flashes, the appearance was 'double' on first exposure and 'single' on the succeeding exposures. 
I. With the brightness $=36$ (c. per sq. meter), two $40 \mathrm{\sigma}$ flashes were distinguished from one $80 \sigma$ flash when the interval was $20 \sigma$; with $15 \sigma$ interval, the one flash and the two flashes looked equally double.

With brightness $=3$, the two were distinguished from the one with i $5 \sigma$ interval.

With brightness $=168$, discrimination was clear at $25 \sigma$; not at $20 \sigma$.

2. With two $25 \sigma$ flashes, and one $50 \sigma$ flash, the difference was clear when the interval was $35 \sigma$, with all the brightnesses, equal 'doubleness' at $30 \sigma$.

3. With two 10 $\sigma$ and one $20 \sigma$ flashes, the discrimination was clear when the interval was $55 \sigma$ for the 3 and 36 brightnesses, and $40 \sigma$ for the 168 brightness. Below these points the 'doubleness' was the same.

Similar observations by Dr. Cobb gave the following results:

I. Two $25 \sigma$ flashes and one $50 \sigma$ flash, with brightness $=3$, 'doubleness' clear at $40 \sigma$ interval. With brightness 36 and 168 , 'doubleness' clear at $30 \sigma$ interval.

2. Two $50 \sigma$ flashes and one $100 \sigma$ flash, with brightness $=3$, clear at $20 \sigma$.

With brightness $=36$, clear at $25 \sigma$.

With brightness $=168$, clear at $30 \sigma$.

3. Two ro $\sigma$ flashes and one $20 \sigma$ flash, with 3 and 36 brightnesses, not clear below $50 \sigma$ (no longer interval used): with I68, clear at $45 \sigma$.

4. Two $75 \sigma$ flashes and one $150 \sigma$ flash, brightness $=3$, clear at $10 \sigma$ interval. Brightness $=36$ and 168 , clear at $15 \sigma$ interval.

On the whole we cannot conclude that increasing the brightness of the flashes increases the distinction of the doubleness of two. This is a matter that is dependent upon the absolute length of the flashes. In subsequent work, carried out on the two observers listed above, and on Dr. George R. Wells, the effect of brightness was brought out directly by trying various intervals in succession with the same flash-lengths. This work, while agreeing with that 
reported above, brought out the further fact that the effect of intensity variations on successive flashes which are hardly distinguished at best because of the shortness of the interval, is not the same as the effect on succession with longer intervals.

These observations are not consistent with the tabulated results, but there is no reason why we should expect them to be so, since the conditions of observation were entirely different. We must always distinguish in problems of this kind variations in the actual observable phenomena established by the experimental conditions, and the variations in the observations of these phenomena which may be due to the same conditions. For example: the sensible content from two (successive) stimulations may be different from the sensible content due to a single stimulation, and yet on account of the circumstances of observation, the difference may not be noted. On the other hand, a sensible content of a certain sort may now be judged like, now be judged different from, a content from which it differs slightly, according as the conditions of observation throw this difference in relief, or minimize it.

\section{My Own Observations}

During the course of the experiments reported above, I acquired a considerable facility in observation, since I watched the flashes while having full knowledge of the stimulus conditions. I did not record my observations during the work with the other observers, since the necessity of conducting the experiments for them, and especially the attention to speed and accuracy in the adjustment between exposures, was a disturbing factor.

Later I made observations (with knowledge) myself under satisfactory conditions. In these cases I worked with the 'progressive procedure,' starting alternately with a setting (width of dark interval) giving no doubleness, and one giving doubleness.

This work was done at night, and the results on different nights did not agree absolutely. There was, however, a 
general uniformity, such as is indicated in Table XIV., in which are given the results on four nights during August. The figures given are not averages, but absolute values in the scale of $5 \sigma$ steps; the points at which (and above which) the flashes were always seen 'double' (d.) and at which and below which they were seen 'single' (s.) on that night under

\section{TABle XIV}

\section{Durlop}

Flash $=500$

r. Aug. 4

\begin{tabular}{c|c|c|c|c|c|c}
\hline \multirow{3}{*}{ Brighteass } & \multicolumn{2}{|c|}{ Dark Adap. } & \multicolumn{2}{|c|}{ Light Adap. } & \multicolumn{2}{|c|}{ Constant Light } \\
\cline { 2 - 7 } & d. & s. & d. & s. & d. & s. \\
\hline I0 & 40 & 30 & 20 & 5 & 20 & 5 \\
36 & $40-50$ & 30 & 20 & 5 & 20 & 5 \\
82 & $40-50$ & 30 & 20 & 5 & 20 & 5 \\
168 & 40 & 30 & $10-30$ & 5 & 20 & 5 \\
\hline
\end{tabular}

2. Aug. 22.

\begin{tabular}{c|c|c|c|c}
\hline \multirow{3}{*}{ Brightness } & \multicolumn{3}{|c|}{ Dark Adap. } & \multicolumn{2}{|c}{ Light Adap. } \\
\cline { 2 - 4 } & d. & s. & d. & s. \\
\hline 3 & 25 & 15 & 20 & 10 \\
10 & 25 & 15 & 15 & 5 \\
36 & 25 & 15 & 5 & $?$ \\
82 & 25 & 15 & 5 & $?$ \\
168 & 25 & 15 & 10 & 5 \\
\hline
\end{tabular}

3. Aug. 23

\begin{tabular}{c|c|c|c|c|c|c}
\hline \multirow{2}{*}{ Bnghteess } & \multicolumn{2}{|c|}{ Dark Adap. } & \multicolumn{2}{c|}{ Light Adap. } & \multicolumn{2}{c|}{ Constant Lght } \\
\cline { 2 - 6 } & d. & .. & d. & B. & d. & . \\
\hline 3 & 20 & 10 & 20 & $5-10$ & 5 & 2.5 \\
10 & 20 & 10 & 10 & $?$ & 5 & 2.5 \\
36 & 20 & $5-10$ & 5 & $?$ & 10 & 5 \\
82 & 20 & 15 & 5 & $?$ & 10 & 5 \\
168 & 20 & $10-15$ & 5 & $?$ & 10 & 5 \\
\hline
\end{tabular}

the conditions indicated. When the threshold varied during the test, the variation is indicated. The observation lasted from one to two hours, with periods of rest for the eyes.

In certain cases, no definite determination was made for the 'single' point. This is indicated by a question mark. 
The series with dark adaptation and light adaptation were taken as in the work on other observers. The results in the columns under 'constant light' were obtained while the object disc was illuminated by the 'tunnel lamp' described above, $(h)$. In this case, the flashes were superimposed on a constantly lighted surface. Except for the illumination of the disc, the room was dark during these observations.

The observations included in Table XIV. were with 500 flashes only; with $25 \sigma$ the results were more uniform; for all brightnesses, with dark adaptation, the double point was at $40 \sigma$, the single, at $30 \sigma$; with light adaptation, the points were $20 \sigma$ and $10 \sigma$ respectively; with light adaptation and constant light in the disc, $20 \sigma$ and $5 \sigma$. With dark adaptation and constant illumination, the single point was $5 \sigma$, but the double point was variable $(10 \sigma-20 \sigma)$. Flashes above $50 \sigma$ (up to $75 \sigma$ ) gave more variable results.

The general influence of light adaptation and constant illumination was demonstrated on a number of persons, including the observers listed above, by a simple method. The sectors were set so that with dark adaptation the two flashes appeared 'single,' or the judgment was 'doubtful.' Then the eye was light-adapted for a short time, and observation showed a striking change, it being possible with any observer to change the judgment from 'distinctly single' to 'distinctly double' by this means. The addition of a constant illumination served the same purpose. With certain settings of the sectors, and a faint constant illumination on the disc, the two flashes appeared 'single'; by increasing the constant illumination a point was reached at which the appearance was clearly double. This point varied with different observers, and at different times.

\section{The Sources of Difficulty}

The results of the investigations of the visual time threshold up to this point are as follows:

I. The effects of brightness of the light are variable, depending on the other factors in such a way that no conclusion can be drawn as yet concerning their effects. 
2. The threshold is lower for the light-adapted eye than for the dark-adapted eye. This holds, at least, for certain light-adaptations.

3. The threshold is lower for an interval marked by flashes added to a continuous stimulation, than flashes in a dark field. This holds for a wide range of constant illumintion, the threshold varying usually with the brightness of the constant illumination up to the point where the additions lose in distinctness.

4. A single flash is frequently seen as a succession of two, and although this 'twoness' may, under proper conditions, be discriminable from actual 'twoness,' these conditions are not easily actualized in quantitative work.

In consequence of this (and, possibly, other factors) quantitative work by the standard methods is not possible; at least the results of such work are unreliable. Special methods must be devised.

5. It is impossible to train observers on the light threshold problem in a limited time (two or three months). Observations are of value only if made by persons having a long training in that particular work. In this respect, the timethreshold problem differs markedly from certain other problems, e. g., of flicker. The length of training required cannot be specified, but possibly should extend over a period longer than a year.

The most interesting question coming out of these observations concerns the apparent doubleness of a single flash under certain conditions. This doubleness of appearance is unquestionable; the flash has at times a striking 'one-two' progression.

This fictitious doubleness is not exclusively a darkadaptation phenomenon, although it is less noticeable with light-adaptation. Constant illumination, on the other hand, even of relatively low brightnesses, completely abolishes it. We might therefore suppose it to be due to an iris-reflex: the stimulation beginning with dilated iris causes a strong contraction and immediate relaxation, so that the light-flux entering the eye drops and rises again causing a depression 
('dimple') in the excitation curve of the retinal process in the same way as in a rapid succession of two flashes.

The occurrence of the flash provokes a strong visual reflex, noticed by every observer. One feature of this reflex is an increase in accommodation: at the end of the stimulation, this accommodation is for a point nearer than the object-disc, and the relaxation necessary to re-accommodate for the disc is easily noticed. Since accommodation and iris-contraction go together this may be taken as indicating the iris factor suggested above.

On the other hand, the chief factor may be retinal. The retinal process may rise to a point higher than its 'normal' for the intensity of stimulation, and then drop back." The drop may be below normal, with an immediate second rise; thus the 'dimple' which normally produces the appearance of doubleness may occur independent of iris-activity.

It is possible that no 'dimple' may be required. The two drops in the sensation,-one following the excessive rise, and the other at the end, may be interpreted as 'twoness.'

The motor-process-adjustment of the eyes-may be connected with the fictitious doubleness through an actual inhibitory discharge to the retina accompanying the discharge to the ciliary muscle. Efferent fibers to the retina are known to exist, although their function is not known.

The motor-process is probably the cause, or connected with, the severe effect of the observations. Both Martienssen and myself felt the effect to a marked degree, the eyes becoming very irritable, and necessitating frequent interruptions of the work.

Instead of being towards the end or in the middle of a very simple experiment, or small group of simple experiments, we are now at the place where it is necessary to take up a large number of points, not so clearly connected with each other as they are contributory to the solution of our initial problem. If any light is to be thrown on these problems, it can come

"Such action of a light stimulation on the retina is called by physicists the 'over-shooting of the sensation.' 
only through the solution of these various problems, each of which involves an extended investigation.

The problem, or group of problems, which stand out above the others in importance, concerns adaptation. I am now installing apparatus and developing methods which may throw new light on this topic. 